\section{SANITARY SUCTION}

Dürr Dental invented the modern day suction system so have a wealth of experience to draw on when it comes to maintenance. If the suction system is not cleaned and disinfected regularly heavy deposits will form which can cause blockages. Suction systems are also a breeding ground for micro-organisms, so need to be thoroughly disinfected to protect against infection as well as odour.

Dürr Dental's Orotol range boasts extraordinary cleaning power and is foam-free, making it popular with nurses. The suction range is available as either a concentrated powder or as a liquid, both of which have an environmentally friendly composition and a pleasant odour.

For more information call 01536526740. Reader response number 50

\section{CALMING CUSTOMISABLE AQUARIUMS}

According to research, having a fish tank in the room can both calm patients and improve staff morale. Aquavista UK has launched a new range of wall mounted fish tanks that are easy to maintain, decorative and feature a customisable display for your practice's logo or a key message.

An aquarium from Aquavista UK containing exotic and tropical fresh water fish starts at less

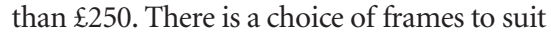
your surgery design - whether it is traditional and elegant or fun and funky. You can also change the frame as often as you like.

Top of the range Aquavista UK aquariums have touch screen controls, auto-feeding and filtration. See www.aquavistauk.co.uk. Reader response number 52

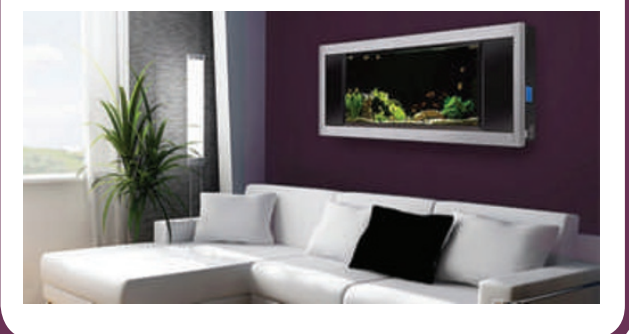

\section{A FASHION CLASSIC}

Grahame Gardner's P785 tunic was developed for the fashioned-focused beauty market but continues to be a hit with the dental market.

The classic style boasts a mandarin style collar and side opening detail, with attractive pearl studs and a tri-button internal security feature.

The P785 represents a more fashionable take on work wear, yet is also smart and professional. The cut and length of the tunic mean that is a very flattering shape for all.

The design has been modified over the past

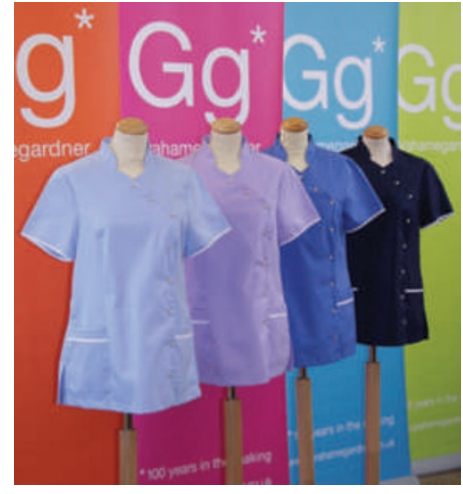

few years, for example with the incorporation of a waterproof pen pocket. Grahame Gardner now stock an extended range of colour combinations. The P785 tunic is available from $£ 16.95$ ( + VAT).

Call 01162556326 or see www.grahamegardner.com. Reader response number 51

\section{SOUTHAMPTON DENTAL NURSE TRAINING}

The Quinn Centre in Southampton, part of the SCA Group, a respected social enterprise organisation, is a one stop shop for dental nurse training. It offers the NVQ Level 3 in dental nursing on a rolling programme that nurses can join at any time, as well as a dental nurse induction workshop running for two days.

The Quinn Centre also provides CPD sessions in legal, ethical and practical developments such as infection control procedures, which dental nurses can attend one day a year, on a Saturday.

The Quinn Centre courses are open to all practising dental nurses whether they are from NHS or private practices. An annual dental training plan will be posted on the Quinn Centre website. See www.scagroup.co.uk.

Reader response number 53

\section{A-PEELING BRUSHES}

Invented by a dental hygienist mum, Heather Phillips, the Baby Banana Infants Teething Toothbrush and Toddler Training Toothbrush encourage children to develop good oral hygiene habits early on.

The banana shaped brushes are soft, bendy and flexible to reduce injury risk and they have an easy to grasp handle. BPA, latex and phthalate free, the brushes are made from non-allergenic, $100 \%$ highest quality silicone and last longer than traditional brushes.

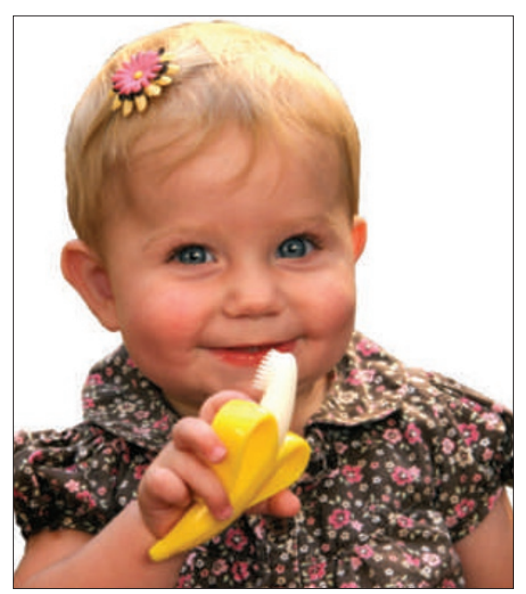

The Infants Teething Toothbrush is for newborns to aged 12 months and gently massages gums and teeth. For toddlers aged one year and up, the Toddler Training Toothbrush will be 'a-peeling' with its fun banana design and will help keep gums and teeth clean and cavities later on.

Both brushes are dishwasher and steriliser safe. www.safababy.com Reader response number 54 